\title{
Research on the Credit System of Constructing Personalized Intelligent e-commerce Logistics
}

\author{
Hongsheng $\mathrm{Xu}^{1,2 \mathrm{a}^{*}}$, Yongliang $\mathrm{Li}^{1,2}$ and Ganglong Fan ${ }^{1,2}$ \\ ${ }^{1}$ Luoyang Normal University, Luoyang, 471934, China \\ 2Henan key Laboratory for Big Data Processing \& Analytics of Electronic Commerce, Luoyang, \\ 471934, China \\ a85660190@qq.com \\ * The Corresponding Author
}

Keywords: Credit; E-commerce; Logistics; Personalized intelligent; Information management system

\begin{abstract}
A good credit system is the basis for the development of e-commerce, so it is particularly important to establish a perfect credit system for e-commerce. E-commerce as a new business mode of motion, it's every movement is trading involves various participants, including both sides involved in the transaction, the electronic commerce website, the third party logistics company, bank, tax bureau, industry and commerce, public security and other agencies, each participant must bear certain credit responsibility. This paper discusses the related problems of e-commerce logistics, and puts forward specific measures for building personalized intelligent e-commerce logistics information management system.
\end{abstract}

\section{Introduction}

Research and Practice on the field of social credit in China has a history of more than ten years, after years of development, the construction of credit system has begun to take shape. But in general, the construction of social credit system in China is still in the initial stage. The enterprise electronic commerce of our country business credit management system is not perfect, most there is no set of enterprise credit management, investigation of customer information lack of transaction, lack of understanding of the customer's credit status, the wrong choice in electronic commerce transaction object, and then default phenomenon is inevitable.

Website business model refers to the commodity trading through the seller's own website. Usually the buyer will make payment to the account designated by the site, and then shipped. This pattern is unidirectional, with the credibility of the site as the foundation; it needs to fully trust the buyer to the seller. This model is mainly applicable to retail Web site.

Social credit system is also called the national credit management system or the national credit system. It is a kind of social mechanism, regulate the market specific role in one country, it aims to establish a suitable for the development of credit market environment, to ensure the transformation of market economy to the credit economy direction, from the original means of payment for the mainstream fashion to change the way of health market mainstream market transactions to credit transactions [1]. This mechanism will establish a new market rules, so that social capital can be formed directly, to ensure a country's market economy, enlarge the market of a country.

The operation of electronic commerce involves many security issues, including financial security, information security, cargo security, business secret [2]. Electronic commerce must be conducted via the Internet, but the Internet does not have the safety of commercial transaction needs. A lot of economic information in the online transfer of funds allocated in the mobile Internet, the security problem can not be solved properly, realize electronic commerce is an empty word. Many users do not want to conduct online transactions is also due to the safety of electronic commerce, reliability skeptical. The security problem of electronic commerce is also involved in the management and legal issues. How to effectively ensure the security of electronic commerce is the key to the implementation of e-commerce. 
In developed countries, due to the development of the market economy is relatively mature, the credit system as a means of administrative control and information release form, in the social economic life plays an important role in identifying [3]. And started is still in the construction of credit system in China, the credit laws and regulations are not perfect, credit information resources are limited and the degree of public is not high, the integrity of the enterprise and individual industry awareness is low, the development mode of credit industry is still in the exploratory stage, the credit system currently applies only to the financial aspects of the business, and not extended to the whole economic field, both the lack of adequate and effective integration, has been unable to meet the needs of the development of socialist market economy of the remote. Electronic commerce has the record can be changed, the complexity of the subjects, the credit information asymmetry and lack of characteristics, determine the credit problems more prominent It is easy to appear in the transaction information, supply, payment and other aspects of credit problems, affecting the user's confidence in online trading.

In order to promote the healthy development of e-commerce industry, on the one hand, we hope that under the traditional business model of credit mode as soon as possible, the credit data sharing as soon as possible; at the same time we consider the need for e-commerce participants to establish the necessary, practical, accord with the characteristics of electronic commerce mode of credit and credit data management mechanism; perfecting the system of credit management that involves many factors, but the credit related legislation, law enforcement is the priority among priorities. We had a "electronic signature law", the future may also need to have the electronic commerce enterprise credit management measures, measures for the Administration of auction transactions online, e-commerce tax invoice and a series of financial policies and regulations. The paper presents research on the credit system of constructing personalized intelligent e-commerce logistics.

\section{Perfecting the Electronic Commerce Credit System and Promoting the Intelligent System of E-commerce Logistics}

The establishment of a government background across sectors, including banking, business administration, public security, enterprise and individual credit evaluation and supervision system of Taxation and other departments to achieve collaborative, cross sectoral, cross industry, cross regional credit information interoperability. Through such a credit platform, to the enterprise to any query, any individual the credit records [4]. Through the automatic operation of credit evaluation model, the information network can provide the evaluation on enterprise credit and personal credit rating, the credit management system. Referring to foreign experience, first from the enterprise credit management system construction, the establishment of enterprise credit information database, and then gradually extended to the personal credit management system and the rapid development. The electronic commerce based on the Internet technology is the best guarantee to build this platform.

Electronic commerce as a commercial activity, credit is also the basis for the existence and development of the electronic commerce and credit services are developing rapidly emerging field, market prospects, from the relationship between the two, on the one hand, e-commerce needs the credit system and credit system is also likely to be first in the field of electronic commerce has widely used and reflected its value, as is shown by equation (1) [5].

$$
\gamma=\frac{\sigma_{u}^{2}}{\left(\sigma_{u}^{2}+\sigma_{v}^{2}\right)}
$$

Because the strongest demand of Electronic Commerce on the credit system, no electronic commerce high risk credit system support; and based on the e-commerce and it is easy to establish a credit system, the flow of information in electronic commerce, capital flow, logistics and electronic signature four mutually cross formation as a whole, in the whole, as long as some integration analysis, technical processing, can establish a credit system, and the credit system is controlled to the electronic 
commerce. Therefore, the integration of electronic Business and credit systems, or the establishment of an electronic business credit system, become a demand, a goal, a task.

Due to continued growth in Internet advertising costs, the site also gradually will need the number of viewers and traffic statistics alone is expected to verify the purchase provided to advertisers, so they will be confident of their money is spent wisely; The results show that enterprises significantly modify the process can rarely be completely successful, and many of them it is therefore established by suffer a big risk right business drivers to modify the program management itself has become a key driver [6]. These include setting the correct procedure for project management, structure and technology, have the right to establish a program (for the team culture signal by senior management) and ensure that all the departments are united the same.

At present, there are quite a few sites did not achieve the network distribution qualifications, but on the network to stately sale of goods, when consumers buy goods at these sites or network platform, then let the customer to the designated account remittance or allow customers to fill out personal information, although Alipay and other intermediary platform, but there are a lot of network marketing is the first payment after delivery, they disappeared after the receipt of payment, because the remaining in the website contact are fake, consumers can not contact the dealer, the website according to the means to cheat customers money. In addition, personal information data is also likely to steal the user to sell the information to others to obtain money.

The lack of credit but also restricted the development of logistics enterprises. The practice of the establishment of the credit system from some major developing countries, the development of the credit industry market is the inevitable requirement to economic development and the reform of the financial system [7]. China has a large-scale development of the objective conditions of credit consumption, which requires the credit intermediary service industry rapid development and for the community to provide comprehensive, true, accurate consumer and business credit report. So as to enhance the information symmetry degree of credit market, credit guarantee logistics market is steady, sustained, healthy development of it. So, in addition to formulate relevant laws and regulations of government departments, the logistics industry must build their own credit channel information at first hand, develop a general logistics information platform, as is shown by equation(2).

$$
Y=\left\{\begin{array}{l}
Y^{*}=\alpha+\beta X+\varepsilon, Y^{*}>0 \\
0, Y^{*} \leq 0
\end{array}\right.
$$

Security model is based on the site or business enterprise for the parties to the transaction to provide security for the features, such as "China food trade network" stipulates that any member can Chinese grain trade online transaction contract to Chinese grain trading company for providing guarantee, to solve the problem of credit risk through this kind of guarantee. This will be the organizer the website or website as a guarantee.

With the model, the biggest advantage is that the two sides through the network transaction reduce the credit risk. Moreover, to complete a guarantee behavior, also have a process to verify the negotiations, increasing transaction costs virtually [8]. Therefore, in practice, this mode of credit generally only suitable for use with the specific organization of the industry. But the electronic commerce website is open to those characteristics the main transaction does not apply.

So, overall, in the four major measures to regulate the activities of e-commerce, credit system can be said to be one of the most flexible and most likely model specification and e-commerce itself to realize the benign interaction, it can be everywhere and can do it. I have great form is beyond shape analysis as above, the electronic commerce and credit system consistency in nature, they can easily do seamless connection, this brings efficiency and convenience of the seamless connection is necessary for electronic commerce. And in the administrative and legal sanctions, we found that to achieve a seamless connection with electronic commerce is very difficult. 


\section{Research on the Credit System of Constructing Personalized Intelligent E-commerce Logistics}

The e-commerce sites have also launched their own plans and business integrity. The logistics in 2002 launched the integrity of business, mainly to solve the network problems. The website of trade credit and ICBC, commercial investigation agencies together to enforce their membership of the business to ensure that engaged in electronic commerce in the member honesty credit the business income of them not only brought tens of millions each year, but also promote the formation of good faith "net community. The integrity of business is mainly based on B2B model.

The web service can be accessed easily by any other client soap and call. And the client can choose the server; this is very effective for the application of e-commerce. Downstream customers through the same client applications, interactive business activities and more upstream businesses, without considering the internal structure of each merchant server, or not need to use special client application for each business.

In the present case, especially the electronic commerce laws and regulations is not perfect, lack of clear laws and regulations to regulate e-commerce. Increase the risk of electronic commerce movement. Although has promulgated the "electronic signature law", but it also has its limitation, and e-commerce is a cross industry more and more, the administrative departments of all regions of the business enterprise actual movement, in the process of e-commerce transactions, the legal issues involved in many aspects, but there is no relevant legislation [9]. Due to the restrictions on the movement of electronic commerce is lack of legal, some traders use the legal gaps and loopholes in online blackmail movement. Take the four operating modes and third party payment credit terms. To some extent, is lack of authority, as is shown by equation (3).

$$
u=\int_{0}^{x} x d x+\int_{1}^{y}\left(\frac{x^{2}}{2}+\frac{1}{y}\right) d y=\frac{x^{2}}{2} y+\ln y
$$

Modern logistics is no longer confined to simple transportation, is an advanced organization and management technology [10]. The use of advanced logistics equipment and technology can realize the automatic acquisition of logistics from the source, to achieve the logistics process full transparency and traceability. Logistics credit platform is the most important to make goods identification intelligent, escort and electronic receipt three.

Accelerate the establishment of the social credit system, perfecting the laws and regulations related to the system. The market economy is a credit economy and legal economy. As a new member of the market economy, e-commerce needs the supporting laws and regulations promulgated as soon as possible. To strengthen the network supervision, especially to some sites may the economic activities and the corresponding website account of, should strengthen supervision and guidance, to introduce the real name system; to set up a network complaint handling mechanism effective, so the network complaints can be resolved promptly and effectively; to perfect the laws and regulations of electronic commerce, the network disputes according to the law, to eliminate loopholes.

\section{Experiments and Analysis}

To speed up the construction of logistics distribution system, one is to gradually open up the market, welcome the domestic and foreign logistics companies to participate in the competition, through competition, the logistics distribution system in China is becoming more and more perfect. The two is to pay attention to the logistics personnel training, in addition to the school personnel training, but also speed up the logistics division occupation qualification is three steps. In the information technology and logistics management and it is flexible and integrated to strengthen logistics management innovation.

The logistics distribution of e-commerce success is directly related to the success or failure of e-commerce, is an important measure of electronic commerce. Intelligent escort refers to the logistics enterprises to adopt the hardware equipment of computer technology and modern network technology, software system and advanced management tools, a series of classification, according to the customer's demand for encoding, consolidation, picking tally work, in accordance with the agreed time and place 
will determine the number and specifications of the goods delivered to the activities and processes of users.

This new logistics mode brings great changes in the field of circulation, more and more enterprises begin to adopt e-commerce logistics distribution mode. Compared with the traditional logistics distribution mode in terms of e-commerce logistics distribution mode with efficient delivery, timely control and simplify the process of advantage.

\section{Summary}

In the field of credit management system is also very important, it directly affects the electronic payment and normal service performance, influence the efficiency and quality of the electronic commerce. The paper presents research on the credit system of constructing personalized intelligent e-commerce logistics.

\section{Acknowledgements}

This paper is supported by Henan key Laboratory for Big Data Processing \& Analytics of Electronic Commerce, and also supported by the science and technology research major project of Henan province Education Department (17B520026).

\section{References}

[1] Bai Zhen $\mathrm{Wu}$. The existing problems and Countermeasures of network marketing in small and medium enterprises. Coastal enterprises and science and technology, 2006, (2): 88-89.

[2] Hongsheng Xu, Ruiling Zhang. Novel Approach of Semantic Annotation by Fuzzy Ontology based on Variable Precision Rough Set and Concept Lattice, International Journal of Hybrid Information Technology Vol.9, No.4 (2016), pp. 25-40.

[3] Yang Qinghua. Talking about the existing problems and Countermeasures of small and medium-sized enterprises to carry out network marketing. Yunnan coal.2011, (1): 74-75.

[4] Han Xiaorui, Luo Xin Fang, Zhu Qian. Construction of the integrity system. mall under electronic commerce modernization, 2008.

[5] H.-s. XU, R.-1. ZHANG, "Semantic Annotation of Ontology by Using Rough Concept Lattice Isomorphic Model", International Journal of Hybrid Information Technology, Vol.8, No.2, 2015, pp.93-108.

[6] Su Dongmei. Analysis of the development and Countermeasures of network marketing for small and medium enterprises in China. Liaoning:.2010 of Dongbei University of Finance and Economics.

[7] For example, the development strategy of network marketing in the era of electronic commerce. Chinese inspirational network.2011.

[8] Cai Sainan. Thinking about the opening and sharing of credit information in the construction of credit system in China. credit, 2011,29 (2): 51-54.

[9] Liao Junfeng, Chen Liping. The credit problems in electronic payment and their social origin. academic research.2007 (11):79.

[10] Li Junrong, the status and legislation of e-commerce credit system, Chinese and foreign enterprise culture,.2001, Z1. 